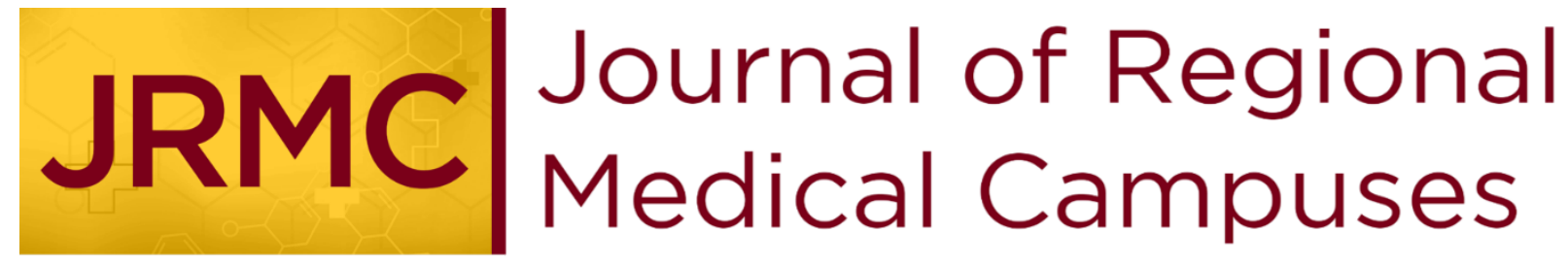

Motivating Factors of and Perceived Barriers to Research at a Canadian Medical University with Regional Campuses: A Cross-Sectional Survey Study

Jennifer Leigh, MD, MSc; Maroof Khalid; Jennifer Tsang, MD, PhD, FRCPC

DOI: https://doi.org/10.24926/jrmc.v4i3.3934

Journal of Regional Medical Campuses, Vol. 4, Issue 3 (2021)

z.umn.edu/JRMC

All work in JRMC is licensed under CC BY-NC

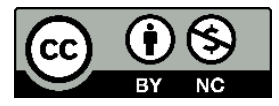




\title{
Motivating Factors of and Perceived Barriers to Research at a Canadian Medical University with Regional Campuses: A Cross-Sectional Survey Study
}

Jennifer Leigh, MD, MSc; Maroof Khalid; Jennifer Tsang, MD, PhD, FRCPC

\begin{abstract}
Introduction

Research training programs are an integral part of a well-rounded medical education. These programs help students contribute to medical knowledge, develop skills in critical evaluation and research dissemination, and they facilitate the training of our future medical researchers. Existing literature suggests barriers including lack of available time and access to projects may hinder a medical student's research training. These barriers likely differ based on the medical school curriculum, and there exists limited data looking at these attitudes in Canadian students, students outside large academic centers, or those in condensed programs. Given this, our study aims to further explore medical students' perceptions, perceived barriers of research in a 3-year Canadian undergraduate medical school with regional campuses.
\end{abstract}

Methods

We conducted a cross-sectional survey of medical students (classes of 2019, 2020, and 2021) representing the main and regional campuses of the Michael G. DeGroote School of Medicine in Ontario, Canada to explore their attitudes towards research. Descriptive statistics were used to describe participant demographics, research background, and attitudes towards research.

Results

Overall, $70.4 \%$ of students identified as being involved in a research project at some point during their medical school tenure. Motivating factors for research participation included the goal of obtaining a residency spot (63.0\%), and interest in their research topic (74.7\%). Barriers to research included perceived lack of available time (31.5\%), and difficulty in finding a research project (44.5\%). Perceived curriculum deficiencies included inadequate education in research methodology and appraisal of scientific literature ( $93.8 \%$ and $90.1 \%$, respectively). Lastly, regional campuses tended to, more often, conduct their research outside of their home campus (43.6\% vs 3.3\%, $<<0.0001)$. Conclusion

The findings from our study highlighted the students' attitudes towards research in a Canadian medical school that has multiple campuses and a shortened curriculum (3-year). It identifies potential areas of improvement from a student perspective, which can hopefully be utilized by medical educators to continue the improvement of medical trainee research training.

\section{Introduction}

Research training programs are an integral part of a well-rounded medical education. These programs facilitate the training of our future medical researchers by helping students develop skills in critical appraisal of medical literature. ${ }^{1,2}$ Existing literature suggests that undergraduate medical students largely view scholarly research programs as positive and/or necessary. ${ }^{3-6}$ These students often believe that their research experiences will contribute

Jennifer Leigh, MD, MSc; Department of Medicine, The University of Ottawa, Ottawa, Canada

Maroof Khalid; Michael G. DeGroote School of Medicine, McMaster University, Hamilton, Canada; Niagara Regional Campus, Michael G. DeGroote School of Medicine, McMaster University, St. Catharines, Canada; Department of Medicine, McMaster University, Hamilton, Canada

Jennifer Tsang, MD, PhD, FRCPC; Niagara Regional Campus, Michael G. DeGroote School of Medicine, McMaster University, St. Catharines, Canada; Department of Medicine, McMaster University, Hamilton, Canada; Niagara Health, St. Catharines, Canada 
to their career progression, help them select their medical specialities, and increase their confidence when applying to their desired residency programs. ${ }^{5}$ Despite these widely held positive beliefs, not all students participate in research activities during their undergraduate medical education. A Canadian survey conducted in 2016 found that only $23.8 \%$ of undergraduate medical students participated in research-related activities, despite $74.2 \%$ believing that they should and $83 \%$ believing that research participation would be valuable. ${ }^{5}$ The current available literature suggests that there are a number of barriers impacting these students' ability to participate in medical research, including perceived lack of time, lack of acknowledgement, and lack of available opportunities. ${ }^{6-12}$

Currently most medical schools in Canada provide students with opportunities to engage and participate in research. ${ }^{2}$ Every research curriculum is different, with some having integrated formal curriculums while others only offer informal opportunities. Students at traditional 4-year undergraduate medical programs, which make up the majority of medical schools in Canada, are encouraged to participate in research opportunities during their summer breaks. ${ }^{2}$ Typically, this occurs through formal summer student research programs, some of which are funded and might not be officially affiliated with the medical schools. ${ }^{13}$ These students often also have dedicated time for research activities throughout the academic year, where they can potentially continue the projects they began during the summer. ${ }^{13}$ Alternatively, students in 3-year undergraduate medical programs, such as that of the Michael G. DeGroote School of Medicine, do not have the same opportunities. Given the condensed curriculum, there is no summer break, dedicated research time, or funding for students to work on research projects. They must conduct their research solely throughout the school year in addition to their other academic responsibilities, therefore making participation in research uniquely challenging. There is also less overall time to complete and hopefully publish their research given the overall program duration is shorter. From a research perspective they are at a unique disadvantage to their peers in 4-year programs.
In addition to being a 3-year undergraduate medical program in Canada, the Michael G. DeGroote School of Medicine is one of few Canadian medical schools to have multiple regional campuses in addition to their main campus. The school is made up of the main campus in Hamilton, Ontario and the 2 regional sites in Waterloo, Ontario and St. Catharines, Ontario respectively. Each year, the medical school admits 203 students, with 147 at the main Hamilton campus and 28 students at each of the regional sites. Following acceptance, students are asked to rank the 3 campuses in order of preference and are matched to their top possible campus choice using their acceptance ranking. All students spend the first 3 months of medical school in Hamilton together, and then go off to their respective sites for the remainder of the program. The regional campuses provide a unique learning experience by having lectures either video conferenced from Hamilton or given locally, tutorials are run by local physicians, and core medical training takes place in community hospitals. In addition to the core education, regional campuses provide a unique research experience where students can work with local, community based researchers. This may not be without its downside, however, as there are often fewer academic researchers, and limited access to specialized fields that may only be present at a large academic center.

Overall, the literature regarding facilitators of and barriers to research participation in undergraduate medicine remains limited. Data on medical students' attitudes and perceptions towards research during undergraduate medical education, as well as what barriers to participating in meaningful research students may face while in medical school in a specifically Canadian population is especially lacking. Even more specifically, there is no existing exploration of these perceptions in medical schools that have a 3year curriculum, or in schools with students at different learning sites. For that reason, our study aims to explore the medical students' perceptions of and perceived barriers to research in a 3-year Canadian undergraduate medical school.

\section{Methods}

A cross-sectional survey study of medical students at the Michael G. DeGroote School of Medicine, McMaster University, was conducted in 2019. This is a 
3-year undergraduate medical program with a main campus in Hamilton, Ontario, and 2 regional campuses in Waterloo, Ontario and St. Catharine's, Ontario. Each academic year, 203 students are enrolled into the program, with 28 being at each of the regional campuses and 147 in Hamilton. At time of acceptance students are asked to rank the 3 campuses in order of preference. They are then allocated to their most preferred campus possible based on their ranking in the admissions process. As a result, students are not guaranteed to be matched to their top choice campus. When it comes to research specifically, students are allowed to travel between campuses to participate in projects.

Participation in our study was completely voluntary. Confidentiality was maintained at all times and no identifying information was recorded in the survey. Ethics approval was obtained from the Michael G. DeGroote's School of Medicine Protocols Review Committee.

\section{Study Tool}

The survey consisted of 39 closed-ended questions (Appendix A) addressed to report the research experiences and attitudes of medical students. The goal was to identify a number of issues: why do students choose to be involved in research, what is the relevance of student research to career aspirations, and what are the barriers to successful participation in research? The questionnaire consisted of 2 parts: demographic information and questions related to research interest and barriers to research. The survey was modified from a validated survey provided by the author (Siemens et al, 2010). The survey was available only in English, and on average took 7 minutes to complete.

\section{Subject Recruitment}

Students were recruited using the McMaster Medicine email list. One email was sent to all students' medical school emails, asking them to voluntarily complete the survey. This included students at all 3 campuses and in all 3 current academic classes (2019, 2020, 2021). Following that, the survey was advertised to all students (classes of 2019, 2020, 2021) through each classes' social media page. A request to complete the survey was posted on each social media page once every 2 weeks, for a total 2 -month period. All responses were anonymous. Each student who completed the survey was given the option to provide their email, so that they could be entered in a drawing to win an iPad, or one of 10 twenty-five-dollar Visa prepaid gift cards.

Data analysis plan

Descriptive statistics were used to describe demographics and research background of students. Mean Likert score was calculated for each item based on the responses of the participants. For ease of reporting, we grouped responses in agreement (Likert 4 and 5), and those in disagreement (Likert 1 and 2). Univariate analysis with Mann-Whitney test was used to determine statistical differences between different campuses. One-way ANOVA was used to determine a statistical difference between the 3 different classes (2019, 2020 and 2021). Statistical significance was defined as $p<0.05$.

\section{Results}

Demographics

Overall, there was a total of 162 respondents with a response rate of $25.9 \%$. The response rate between the 3 classes varied, with 42 participants (25.9\%) being from the class of 2019, 47 (29.0\%) from the class of 2020, and 73 (45.1\%) from the class of 2021. Of the total responses, 100 (61.7\%) were from Hamilton Campus, 46 (28.4\%) from the Niagara Regional Campus, and 16 (9.9\%) from the Waterloo Regional Campus. In total, 139 (85.8\%) respondents reported that they had chosen Hamilton as their primary campus in the initial campus lottery, with 100 (61.7\%) respondents actually ending up at the Hamilton campus. Of the students at regional campuses, 40 (64.5\%) students had actually reported Hamilton to be their first-choice campus, whereas 99 (99\%) students at the Hamilton campus had chosen it as their first choice. The average age of students was 23.8 years (Table 1 ).

\section{Research Experiences}

Overall, 114 (70.6\%) of students had a post-secondary education background in life or health sciences (Table 1). The majority of students had prior research experience ( $n=145,89.5 \%$ ) with that mostly commonly in the form of a university undergraduate thesis project ( $n=59,38.6 \%$ ). There was a significantly greater proportion of students at regional campuses 
with graduate degrees $(n=18,29 \%)$, as compared to Hamilton campus $(n=12,12 \%, p=0.005)$.

There were overall 115 students (70.4\%) who had participated in at least one research project to date in medical school. The most common type of research that the students were involved in was quality improvement, followed by chart reviews (Figure 1). The least common type of research that students were involved in were clinical trials (Figure 1). Of students who participated in research projects, 89 (77.4\%) were able to present their research in the form of a poster or podium presentation, and 36 (27.2\%) were able to publish a peer-reviewed paper. There was a total of $8(26.7 \%)$ students with graduate degrees as compared to 39 (29.5\%) students without graduate degrees who did not participate in any research to date during medical school.

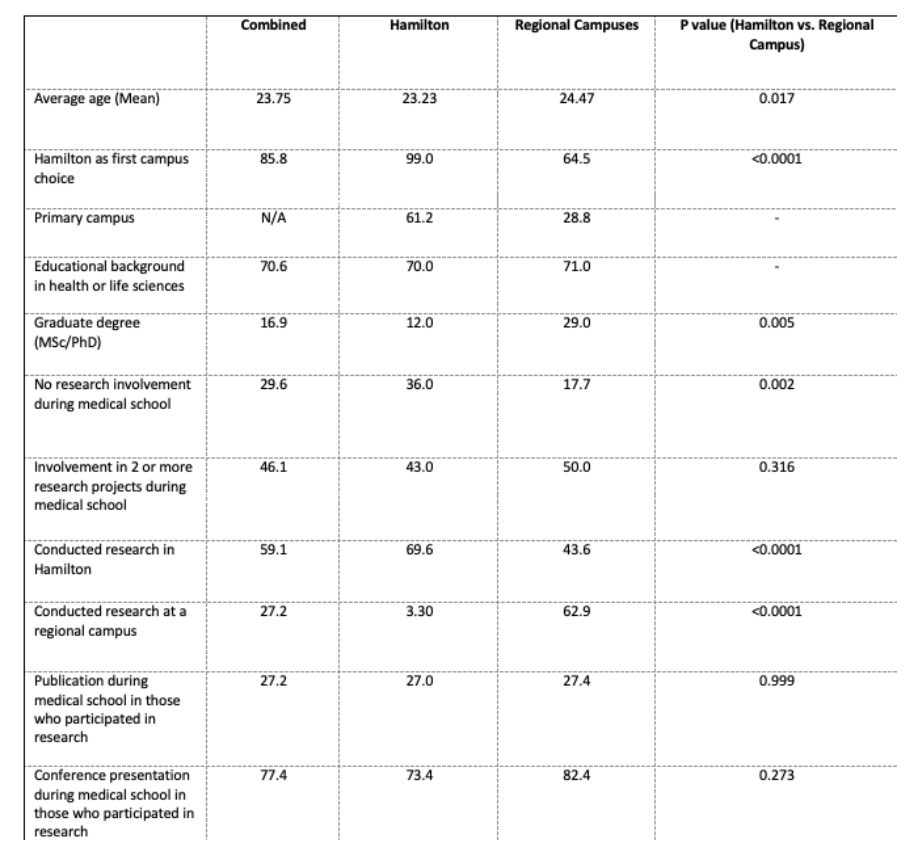

Table 1. Demographics and research experiences of survey participants. Data is represented as combined (all respondents), Hamilton, or Regional Campuses (Waterloo and Niagara combined). Represented as percent participants from that campus. The $p$-value is based off of a comparison of Hamilton to regional campus students.

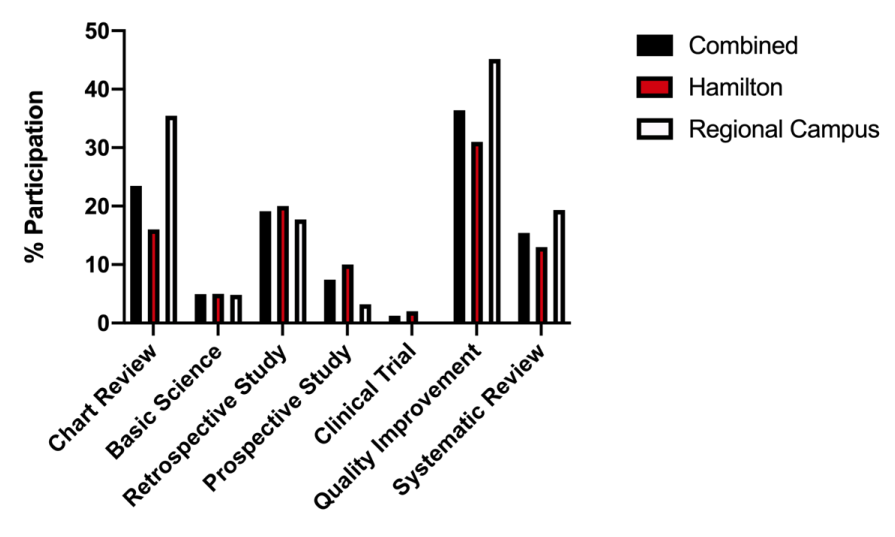

Type of Research Conducted

Figure 1. Type of research students participated in throughout medical school. Students responding to the study were asked to report what type of research they are involved in. Data is represented as the \% of students participating in each type of research. It is separated into all students (black), Hamilton students only (red) and regional campus students only (white).

Motivating Factors for Research Participation As part of the survey, students were asked about their attitudes towards the importance of research, their involvement in research, and perceived barriers to partaking in research during their undergraduate medical education (Table 2). The majority of students cited the goal of obtaining a residency spot as a motivating factor for research participation $(n=102$, $63 \%$ ). They also believed that it was an important factor in helping them obtain that residency spot ( $n=124,76.5 \%)$. Interestingly, only $22(13.6 \%)$ of students felt that it should be an important criterion for acceptance to a residency program. Just over half of students intended on pursuing a residency in Family Medicine ( $n=89,55 \%)$, with Internal Medicine being the second most popular discipline $(n=56$, 34.6\%). Most students ( $n=115,71.0 \%$ ) believed being involved in research would help them achieve their long-term career goals. Lastly, close to three-quarters of students cited that they were involved in research because of their interest in the topic $(n=121,74.7 \%)$.

Barriers to Research Participation

Barriers to involvement in research included perceived lack of available time $(n=51,31.5 \%)$ and perceived difficulty in finding a research project $(n=72,44.5 \%)$. A total of 99 (61.1\%) students felt that there should be time set aside in the curriculum to pursue research interests. Less than one-third of 
students felt that their research supervisors provided adequate guidance and instruction towards research $(n=52,32.1 \%)$. Students also believed that it was very hard to present their research at non-medical school forums ( $n=37,22.8 \%)$ and to publish in a non-medical school journal $(n=43,26.5 \%)$. Lastly, very few students felt that training in research methodology $(n=10$, $6.20 \%)$ and interpreting scientific literature was adequate $(n=16,9.87 \%)$.

Differences Between Main and Regional Campuses Responses from students of the main campus and regional campuses were compared, as reported in Table 1 and 2. Students of the regional campuses were on average older (mean age of 23.23 (SD 2.1) versus 24.47 (SD 3.2), $p=0.0167$ ) and more likely to have a graduate degree ( $12 \%$ vs $29 \%, p=0.005)$. A larger proportion of main campus (Hamilton) students did not participate in research during medical school ( $n=36,36 \%)$, compared to students of regional campuses $(n=11,17.7 \%, p<0.005)$. Regional campus students also tended to participate in more projects, however this was not statistically significant. It was apparent that the majority of students participated in research projects at their home campus: 69 (69\%) Hamilton campus students conducted research in Hamilton, and 39 (62.9\%) regional campus students conducted research at their respective regional campuses. One notable trend was that students from regional campuses were more likely than their counterparts to conduct research at a different campus $(43.6 \%$ versus $3.3 \%, p<0.0001)$. Despite main campus students more often completing their research at an academic center, there was no difference in the percentage of students publishing their work in form of a poster or podium presentation (Hamilton: $n=47$ [73.4\%] vs Regional: $n=42$ [82.4\%], $p=0.273$ ) or peer-reviewed publication (Hamilton: $n=17$ [27\%] versus Regional: $n=14$ [27.4\%], $\mathrm{p}=0.999)$.

There was, however, a significant difference in the proportion of students who presented at conferences between regional campus students who travelled for research ( $n=20,64.5 \%)$ compared to those regional students who conducted research at their home base $(n=22,100 \%, p=0.0014)$. There was no significant difference between these 2 groups in the proportion who published their research (Travel: $n=8$ [25.8\%] vs No travel: $n=7$ [31.8], $p=0.76$ ).

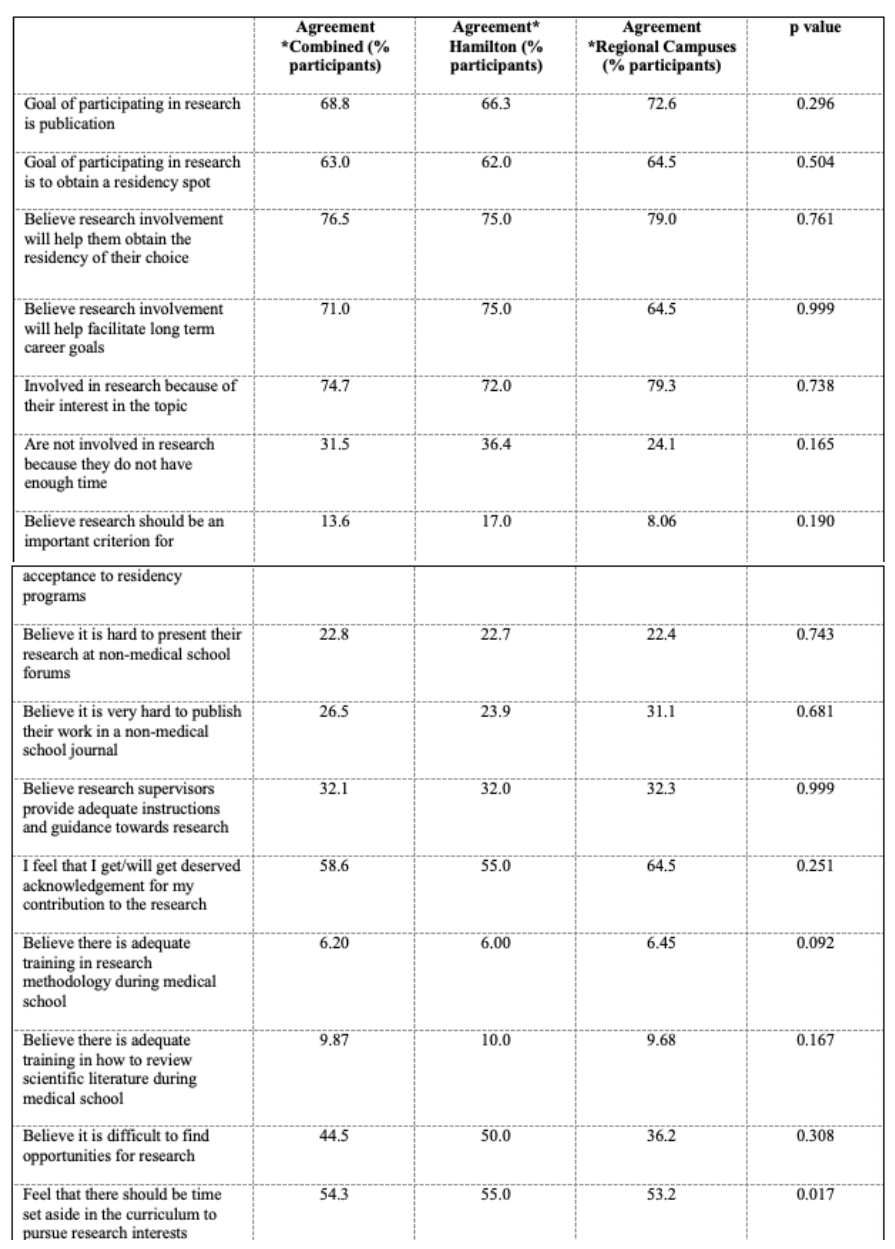

Table 2. Attitudes towards research of students who participated in the survey.

Students were asked to answer the above questions using a Likert scale. Results are divided into combined (all respondents), Hamilton students only, or regional campus students only (Waterloo and Niagara). Presented as \% respondents in agreement with the statement, which is defined as having either answered to agree or strongly agree on the Likert scale. The $p$ value is based on Hamilton versus regional campuses.

Differences between graduating classes Research participation and attitudes towards research stratified by graduating year are outlined in Table 3. The most senior students, who were those in the class of 2019, had significantly more research participation (2019: $n=34$ [81\%], 2020: $n=36$ [76.6\%], 2021: $n=35$ [47.9\%], $p=0.0002)$, presentations at conferences (2019: $n=37$ [88.1\%], 2020: $n=21$ [44.7\%], 2021: $n=33$ [45.2\%], $p<0.0001)$, and publications 
during medical school (2019: $\mathrm{n}=15$ [35.7\%], 2020: $n=13[27.7], 2021: n=9[12.3], p=0.01)$. There was a trend where the class of 2020 felt that participating in research would help them obtain the residency of their choosing (2019: $n=23$ [54.8], 2020: $n=39$ [83.0], 2021: $n=50$ [68.5], $p=0.007$ ), and stated that their goal of partaking in research was to obtain said residency spot (2019: $n=21$ [50.0], 2020: $n=36$ [76.7], 2021: $n=40[54.8], p=0.004)$. They also were more likely to think that it should be an important criterion for acceptance into residency (2019: $n=4$ [9.52], 2020: $n=10[21.3], 2021: n=5[6.85], p=0.0494)$. There was a significant difference between the 3 years in belief that research methodology training was adequate in medical school (2019: $n=1$ [2.98], 2020: $n=6$ [12.8], 2021: $n=3[4.11], p=0.001$ ), however the proportion of patients who felt this overall was low. There was no significant difference in proportion of students who felt training in scientific literature was adequate, or those that believed presenting at non-medical school conferences and publishing in non-medical school journals was difficult.

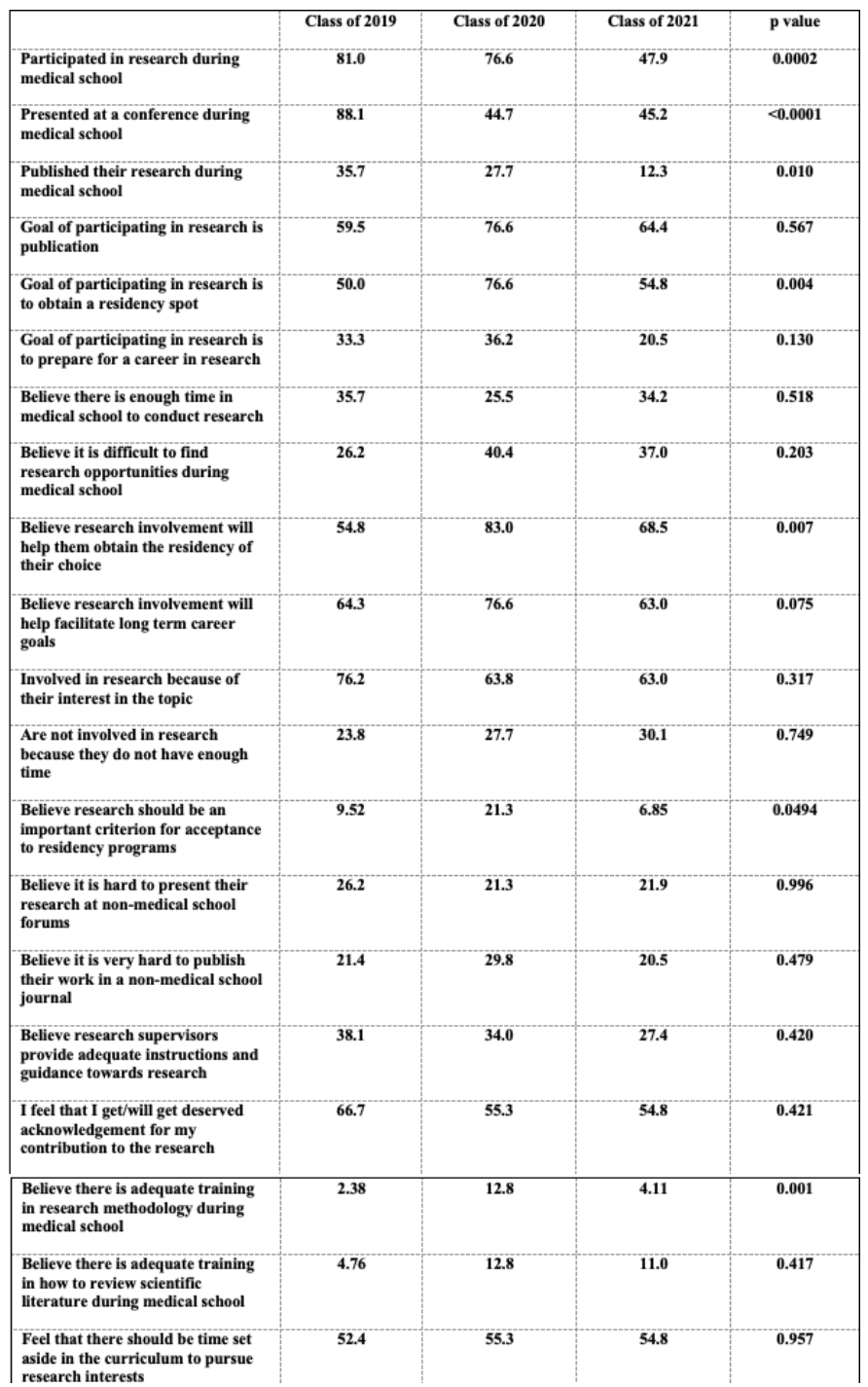

Table 3. Attitudes towards research of students who participated in the survey, stratified by graduating class. Students were asked to answer the above questions using a Likert scale. Results are divided into students from the class of 2019, 2020 and 2021. Presented percentage of respondents who are in agreement with the statement, which is defined as having either answered to agree or strongly agree on the Likert scale. The $p$ value reflects analysis of the difference between the 3 groups.

\section{Discussion}

Our study is the first to describe the research landscape for medical students at a 3-year undergraduate medical school, and the differences between main and regional campuses. It highlights important demographics and attitudes towards research involvement, which can ideally be used to 
improve the research experiences of this unique student population. With a condensed (3-year) undergraduate medical program, the Michael $G$ DeGroote School of Medicine provides different challenges for students compared to their peers enrolled in 4-year undergraduate medical programs, including less available time to participate in research. Additionally, having students at both academic centers and affiliated regional sites leads to even further variation in research experiences. The majority of undergraduate medical training for regional campus students occurs away from an academic center, and by nature of this, students have less local access to academic researchers, resources, and research in highly specialized fields that are not available in community hospitals. This can potentially lead to a different research experience. Identifying areas of weakness in the research curriculum as perceived by students such as that done in our study is key to the ongoing growth and development of both 3-year curriculums and regional programs. A systematic review and meta-analysis found that there are 4 main factors that predict whether a student participates in research during medical school: previous research experience, greater academic success, completion of a graduate degree at the time of matriculation, and concerns that academicians command less income than nonacademicians. ${ }^{3}$ A separate review found that little acknowledgement in publication and lack of available protected time were potential barriers to participation. ${ }^{8}$ Outside of the concern about potential income, these barriers are consistent with those found in our study. Specifically, lack of available time was widely perceived as a barrier to research participation by the students in our study and should serve as an area for medical schools to focus on. There is likely an even greater time constraint in a 3year curriculum as students at traditional 4-year programs often use their summer vacations to participate in research, which is an opportunity that students enrolled in 3-year curriculums are not afforded. ${ }^{13-14}$ Additionally, students in 3-year programs are already tasked with having to learn the same amount of medical knowledge in less time. Given this, strategies to address this barrier will be unique to the shortened timeline. The Michael G. DeGroote School of Medicine is not the only condensed curriculum in North America, and thus this information can be applied to other 3-year programs as well. ${ }^{14}$

In addition to lack of available time to participate in research, close to half of the surveyed students felt that there was a lack of available research projects. There are many contributing factors including shortened curriculum and thus time to find projects, as well as limited student access to researchers especially in regional sites. While there was no statistically significant difference between students of regional campuses and main campus, there was a trend towards more regional campus students feeling that it was difficult to find a project. Additionally, there was a significantly larger proportion of medical students at regional campuses who travelled to another campus in order to conduct their research, instead of simply conducting it at their home campus. This travel time also potentially impacts their research productivity, as evidenced by our finding that regional campus students who did not travel for research were more likely to have presented at a conference. Some highly specialized areas of medicine are only present at academic centers, making it impossible for regional students interested in these fields of medicine to find projects at their home campus. ${ }^{15}$ This highlights an important difference between the 2 types of campuses, and a potential barrier for regional campus students to partake in research. Universities with regional sites should focus on further improving the research experiences of their students with innovations such as the implementation of local research teams who act to support and engage students and local faculty in their research endeavors. ${ }^{15}$ This program has been implemented at the Michael G. DeGroote School of Medicine and has led to expansion of the research programs at each regional site.

Perceived inadequate research curriculum was another barrier identified in our study. An overwhelming majority of students felt that training in both research methodology and appraisal was inadequate. The proportion of students who felt this way in their first and final year of the program was largely similar, suggesting that it is a problem throughout the whole 3-year curriculum. This is again similar to that found in prior Canadian surveys, where only $15 \%$ of students felt there was adequate training in research endeavors, and $25 \%$ agreed that there was adequate training in appraising scientific 
literature. ${ }^{5}$ As these numbers are similar to those in our study, it highlights that feelings of inadequate research training are a widespread concern for Canadian medical students regardless of duration of medical school. Being able to interpret and translate research is an important aspect of any medical career, and the research curriculum offered by undergraduate medical schools plays a key part in teaching clinicians to do so. In order to address this barrier, it is important that medical schools ensure that they dedicate time to a mandatory research curriculum as part of the CanMEDS framework (scholar role), which not all Canadian medical schools currently do. Implementing mandatory evidencebased medicine training and research methodology into the medical school curriculum may be some such ways that schools can further improve their curriculums. The use of flexible online research education modules tailored to each students' needs could also be used to supplement students' education needs and to fulfill the scholar role of the CanMEDS framework.

There are a few limitations to the present study that should be highlighted. First, the data from our study is taken from a small sample size, with only $25.9 \%$ of current medical students responding to the survey. This is likely a product of our ability to only reach our intended audience through one email and social media posts, as well as the survey fatigue that is generated in medical schools. Secondly, the data is taken from a survey where students were asked to self-report, which precludes us from verifying the data. Lastly, while we are able to see what the attitudes towards research, and research demographics for medical students are, we are unable to elucidate the reasons behind these. For example, while we found that a significant proportion of medical students at regional campuses travel for their research projects, we were unable to determine why this is from the structure of our survey. This highlights the need for future small group sessions to help better tease out these factors.

\section{Conclusions}

The findings from our study are unique as they highlight students' attitudes towards research during medical school in a specifically Canadian population. Additionally, it is the first to explore these attitudes in a 3-year medical school curriculum with both main and regional campuses. All physicians regardless of whether they intend on having active research careers need a baseline level of research competency, and this training process often starts during medical school. Additionally, the role of medical scholar has been adopted by the Royal College of Physicians and Surgeons as a core competency in specialty training, thus it is important that medical students at least obtain some formal training prior to entering residency. The information we present identifies potential areas for medical schools to improve their research curriculum, and hopefully improve the research experiences of students. Further in-depth analysis into why there exists differences in participation and attitudes between main campus and regional students through small focus groups of students would be highly beneficial in future planning.

\section{References}

1. Kondro W. Eleven satellite campuses enter orbit of Canadian medical education. CMAJ. 2006; 175(5):461. https://doi.org/10.1503/cmaj.060954

2. Ellaway R and Bates J. Distributed medical education in Canada. Can Med Educ J. 2018;9(1):e1-e5

3. Chang $Y$ and Ramnanan CJ. A review of literature on medical students and scholarly research: experiences, attitudes, and outcomes. Acad Med. 2015; 90(8):1162-73. 10.1097/ACM.0000000000000702

4. Weaver A, McCraw TR, Fifolt M, Hites L and Lorenz RG. Impact of elective versus required medical school research experiences on career outcomes. J Investig Med.

2017;65(5):942-948. http://dx.doi.org/10.1136/jim-2016$\underline{000352}$

5. Siemens DR, Punnen S, Wong J and Kanji N. A survey on the attitudes towards research in medical school. BMC Med Educ. 2010; 10(4). 10.1186/1472-6920-10-4

6. Amgad M, Tsui MMK, Liptrott SJ, Shash E. Medical student research: An 
integrated mixed-methods systematic review and meta-analysis. PLoS One. 2015;10:1-31. https://doi.org/10.1371/journal.pone.0 127470

7. Abushouk Al, Hatata AN, Omran M, Touniss MM et al. Attitudes and perceived barriers among medical students towards clinical research: A cross-sectional study in an Egyptian medical school.J Biomed Educ. 2016; Article ID 5490575, 7 pages

8. Bhagavathula AS, Bandari DK, Tefera YG, Jamshed SQ, Elnour AA and Shehab A. The attitude of medical and pharmacy students towards research activities: a multicenter approach. Pharmacy. 2-17; 5(4):55. https://doi.org/10.3390/pharmacy504 $\underline{0055}$

9. Memarpour M, Fard AP, and Ghasemi R. Evaluation of attitude to, knowledge of and barriers toward research among medical science students. Asia Pacific Family Medicine. 2015;14(1). https://doi.org/10.1186/s12930-0150019-2

10. Soe HH, Thran N, Lwin H, Htay M, Phyu $\mathrm{K}$ and Abas A. Knowledge, attitudes, and barriers toward research: The perspectives of undergraduate medical and dental students. J Edu Health Promot. 2018;7(23). 10.4103/jehp.jehp_61_17

11. Mohd I, Bazli MY, and O'Flynn S. and Universiti Sains Malaysia. 2013: Social and Behavioral Sciences. 116:26452649

12. Nel D, Burman RJ, Hoffman R and Randera-Rees $\mathrm{S}$. The attitudes of medical students to research. 2014. SAMJ. 104(1). https://doi.org/10.7196/samj.7058

13. Patel S, Walsh CM and Udell J. Exploring medically related Canadian summer student research programs: a National cross-sectional survey study. 2019. BMC Medical Education. 19(14)
14. Raymond J, Kerschner JE, Hueston WJ and Maurana $\mathrm{C}$. The merits and challenges of three-year medical school curricula. 2015. Academic Medicine. 90(10):1318-1323

15. Cathcart-Rake W and Robinson M. Promoting scholarship at regional medical campuses students. 2018. Journal of Regional Medical Campuses. 1:

16. Galletly ,Chur-Hansen A, Air T and Chapman I. Academics of the future? A survey of final year medical students. 2009. Australas Psychiatry. 17(6):502-505. https://doi.org/10.1080/103985609032 $\underline{84935}$ 